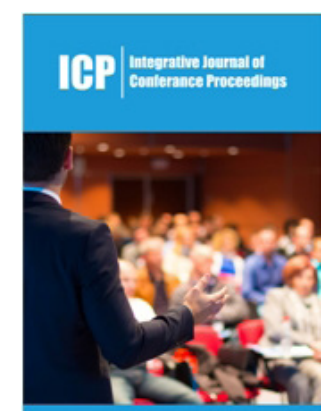

*Corresponding author: MAK Mian, Agronomy Division, Bangladesh Agricultural Research Institute, Gazipur, India

Submission: 侢 January 25, 2021

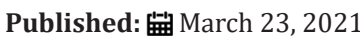

Volume 2 - Issue 4

How to cite this article: MAK Mian Chemical Pesticide Tends Lower Appreciating Alternatives of Pest of Control: Bangladesh Perspective. Int J Conf Proc. 2(4). ICP. 000544. 2021.

Copyright@MAK Mian, This article is distributed under the terms of the Creative Commons Attribution 4.0 International License, which permits unrestricted use and redistribution provided that the original author and source are credited.

\section{Chemical Pesticide Tends Lower Appreciating Alternatives of Pest of Control: Bangladesh Perspective} MAK Mian*

Agronomy Division, Bangladesh Agricultural Research Institute, Gazipur, India
Introduction

Pesticide is commonly used for growing more food successfully to feed the increasing population of Bangladesh. It is a great challenge to provide food to people coping with the demand of nation. Consequently, high inputs like fertilizer, irrigation, pesticides were adopted to enhance crop productivity. Now, it is well known that pesticide has many harmful effects. Extensive expose of pesticides resulted in contamination of air, soil, water and food [1], interring into the food chain caused human health hazard and diseases [2]. Pesticide can cause shortterm adverse health effects, called acute effects, as well as chronic adverse effects. Stinging eyes, rashes, blister, blindness, nausea, dizziness, diarrhea and death are some examples of acute effect. Again, some examples of chronic effects are cancers, birth defects, diabetes, reproductive harm, neurological and developmental toxicity, immunotoxicity and disruption of endocrine system [3]. Infants and young children are more susceptible than adults to the effect of pesticides. Farmer workers and pesticides applicators are more vulnerable because of grater receiver. Pesticides are poisonous chemicals that included insecticides, fungicides, herbicides and rodenticides in Bangladesh context [4]. About 500 chemical pesticides and 43 bio-pesticides are registered in Bangladesh [5]. Earlier of 1990s, pesticides application was limited afterwards it increased reaching peak in 2008. After that, consumption of pesticides showed reducing trend as the awareness grown of people about harmful effects of pesticides. Pesticides is a chemical poison called "silent killer of lives" [6]. Scientists are trying to develop bio-pesticides from many botanicals and organic sources. Integrated Pest Management (IPM) packages are also encouraging for save food production in Bangladesh. Pheromone trap are popularly used by the farmers in many crops specially in cucurbit vegetable crops. Moreover, different traps are used as alternative of chemical pesticides application for insect control. Therefore, the paper is written reviewing the real situation of pesticide application with an alternatives of pest control method for growing more food in Bangladesh.

\section{Methodology}

Pertinent data and information were collected from different secondary sources like Bangladesh Bureau of Statistics [4], Annual Reports and Publications of Entomology Division and horticulture center (Bangladesh Agricultural Research Institute) [7,8], Published article of different Scientists and Organizations. Present scenarios of bio rational pesticides in Bangladesh were cited and discussed. Analysis was done to observe the status of pesticides and efficiency of pesticides with the relation of productivity of food crops. Pesticides includes insecticides, fungicides, herbicides and rodenticides whenever food crops incudes all cereals, pulses, oilseeds, tuber crops (potato and sweet potato), spices and condiments, vegetables and fruits in the study.

Productivity or Efficiency of Pesticides (PE) was calculated according to [9] as follows.

Productivity $(\mathrm{PE})=($ Total food crop production $(\mathrm{t})$ in a year $) /($ Total pesticide consumption $(\mathrm{kg})$ in a year)

Change $(\%)=($ Amount in present year-Amount in last year $) /($ Amount in last year $) \times 100$ 


\section{Results and Discussion}

\section{Food production and pesticide consumption}

Food production increased $43.46 \%$ from $1988-1989$ to 1999 $2000,84.30 \%$ from $1999-2000$ to $2009-2010$ and $29.16 \%$ from 2009-2010 to 2018-2019 (Table 1). The results indicated that the growth rate was found the highest (84.30\%) in 2009-2010 from 1999-2000. Amount of pesticide was also consumed higher in 2009-2010 (Table 1). This was happed due to higher growth rate of food crops in 2009-2010. Changed (\%) of pesticide was noticed higher in 1999-2000 from 1988-1989 followed by 20092010 from 1999-2000 while the negative value was noticed in 2018-2019 from 2009-2010. The results revealed that pesticides use showed deceasing tend from 2008 (Figure 1). At earlier of 1990s, pesticides consumption was lower (11367.20MT of KL), then it gradually increased reaching at the peak (48690.19MT or KL) in 2008, afterward it showed decreasing trend (Figure 1). Decreasing trend occurred due alternate use of pesticide like biopesticide, pheromone trap, other traps, use of predators, IPM, clean cultivation etc. Productivity was found higher (3.95t/kg) in
1988-1989 followed by 1999-2000 and 2018-2019 while giving the lowest value $(1.25 \mathrm{t} / \mathrm{kg})$ in $2009-2010$ (Table 1$)$. The results indicated that $1 \mathrm{~kg}$ pesticide was required to produce $1.25-1.95$ ton of food crop (Table 1).

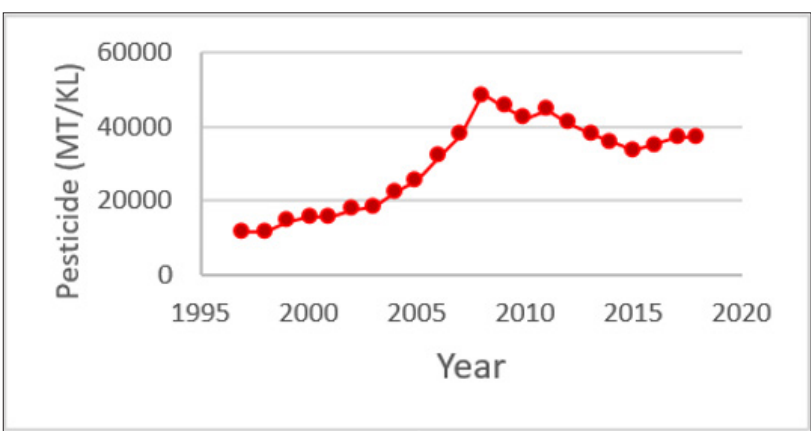

Figure 1: Status of pesticide use in Bangladesh (1997 to 2019).

Source: Adapted from Bangladesh Bureau of Statistics (BBS)

Table 1: Food crop production and pesticide consumption in Bangla (1988-1989 to 2018-2019).

\begin{tabular}{|c|c|c|c|c|c|}
\hline \multirow{2}{*}{ Year } & \multicolumn{2}{|c|}{ Food Crop Production } & \multicolumn{2}{c|}{ Pesticide Consumption } & Productivity \\
\cline { 2 - 6 } & ‘000’ MT & Changed (\%) & Pesticide (MTor KL) & Changed (\%) & (t/kg) \\
\hline $1988-1989$ & 19951 & $\%$ & 5051.01 & 209.4874 & 1.83 \\
\hline $1999-2000$ & 28622 & 43.46 & 15632.24 & 170.2148 & 1.25 \\
\hline $2009-2010$ & 52749 & 84.3 & 42240.63 & -11.9632 & 1.83 \\
\hline $2018-2019$ & 68130 & 29.16 & 37187.28 & - & 1.19 \\
\hline Sd & 22083 & - & 17621 & - & 2.22 \\
\hline Mean & 42363 & - & 25028 & \\
\hline
\end{tabular}

\section{Scenario of alternatives pest control methods}

Use of different bio pesticides are forwarded in Bangladesh (Table 2). Some examples are given about insects and diseases control of vegetables and fruits. Use of bio-pesticides are getting popularity for safe food production. Safe food markets are

Table 2: Some effective bio-pesticide commonly used in Bangladesh.

\begin{tabular}{|c|c|c|}
\hline Insect & Crop & Bio-Pesticide \\
\hline Jassid (Amrasca biguttula) & Brinjal & \multirow[t]{4}{*}{ Bioneemplus, Phytomax, Phizimite, Biotrin } \\
\hline Thips (Thrips palmi) & Brinjal & \\
\hline White fly (Bemisia tabaci) & Brinjal & \\
\hline Aphid (Aphis gossypi) & Brinjal & \\
\hline Leaf miner (Tuta absoluta) & Tomato & Spinosad (Tresser, Success) Biotrin \\
\hline Bana Beel (Nodostoma viridipennis ) & Banana & Tresser, Success \\
\hline Fall armyworm (Spodoptera frugiperda) & Maize & Tresser, Success, Clorantanipl \\
\hline Jassid (Amrasca biguttula) & Okra & Bio-clean \\
\hline Pea Aphid (Acyrthosiphon pisum) & Pea & Neem oil (botanical) \\
\hline \multicolumn{3}{|l|}{ Diseases } \\
\hline Damping off, Wilting, foot and root rot, root knot, (Fusarium) & vegetables & Trico compost \\
\hline Trico liched & & \\
\hline
\end{tabular}

organizing in different parts of Bangladesh. People try to understand the dangerous residual effects of pesticides on human health. Other than pesticides, different packages of pest management like pheromone trap, other trap, IPM, predator, clean cultivation, alternate cropping, crop rotation, intercropping etc. are encoring and getting popularity in Bangladesh. 


\section{Source: Adapted from BARI (2019 \& 2020)}

\section{Conclusion}

Alternative pest control methods rather than pesticide use are getting popularity for safe food production in Bangladesh. Consequently, total pesticides consumption showed reducing trend in Bangladesh indicating green world.

\section{Acknowledgment}

The author acknowledged to the researchers and scientists, organizations, whose information are cited in the papers.

\section{References}

1. Ahmed MS, Prodhan MDH, Begum A, Afroze M, Sarker D (2020) Annul report entomology division. Bangladesh Agricultural Research Institute (BARI), Gazipur, India, pp. 271-272.
2. EPA (2017) Environmental protection agency, USA

3. Anonymous (2021) CPR: Californians for pesticides reform. Pesticides \& human health, USA.

4. BBS (Bangladesh Bureau of Statistics) (1995-2019) Ministry of planning govt, Peoples republic of Bangladesh, Dhaka, Bangladesh.

5. Department of Agricultural Extension (DAE) (2020) Plant protection division. Kharambari, Dhaka, Bangladesh.

6. Balakumar P, Chakkarwar VA, Kumar V, Jain A, Reddy J, et al. (2008) Experimental models for nephropathy. J Renin Angiotensin Aldosterone Syst 9(4): 189-195.

7. BARI (Bangladesh Agricultural Research Institute) (2019) Booklets and Leaflets, Entomology division.

8. BARI (Bangladesh Agricultural Research Institute) (2020) Horticulture Research Centre (Pathology), Leaflet, P4.

9. Rahman S (2013) Pesticide's consumption and productivity and potential of IPM in Bangladesh. Sci Total Environ 445-446: 48-56. 